\title{
Clinical Decision-Making among Critical Care Nurses: A Qualitative Study
}

\author{
Mahmoud Maharmeh, Jafar Alasad, Ibrahim Salami, Zyad Saleh, Muhammad Darawad \\ Faculty of Nursing, The University of Jordan, Amman, Jordan \\ Email: m.maharmeh@ju.edu.jo, jalasad@ju.edu.jo, i.salami@ju.edu.jo,Zyad.saleh2@ju.edu.jo m.darawad@ju.edu.jo
}

How to cite this paper: Maharmeh, M., Alasad, J., Salami, I., Saleh, Z. and Darawad, M. (2016) Clinical Decision-Making among Critical Care Nurses: A Qualitative Study. Health, 8, 1807-1819.

http://dx.doi.org/10.4236/health.2016.815173

Received: October 9, 2016

Accepted: December 13, 2016

Published: December 16, 2016

Copyright $\odot 2016$ by authors and Scientific Research Publishing Inc. This work is licensed under the Creative Commons Attribution International License (CC BY 4.0).

http://creativecommons.org/licenses/by/4.0/

\begin{abstract}
The purposes of this study were to describe the decision making process and decision activities of critical care nurses in natural clinical settings. An exploratory descriptive approach utilizing both interview and observation methods, was used for data collection. The study involved twenty four critical care nurses from three hospitals in Jordan. Participant observation was performed to understand the routine clinical decisions made by Intensive Care nurses. About 150 hours of observations were spent in the involved Intensive Care Units. Nurses were interviewed to elicit information about how they made decisions about patient's care. The study revealed that the most common model nurses tend to use was intuitive model in order to observe the cues relating to the patient's situation. Data revealed that the decision making process is continuous and that experience is one of the main factors that determine nurses' ability to take decisions. Five themes were generated from the data: on-going process, autonomy, experience/power, joint/ethical decisions, and advocacy. Critical care nurses were seen to be sensitive to the patient's verbal and non-verbal cues; they were able to respond to these evidences to ensure that the patient's condition did not deteriorate. Critical care nurses are likely to be more confident and effective when dealing with patient's changing situations with more experience.
\end{abstract}

\section{Keywords}

Critical Care, Decision Making, Jordan, Nursing

\section{Introduction}

Global health is undergoing wide changes. These changes embrace developments in technology and in developing new methods for patient care [1]. These advances in technology have led to an increase in the complexity of nurses' decision making particularly in critical care areas where nurses usually care for patients with multiple prob- 
lems [1] [2]. Indeed in critical care settings clinical decisions are frequently made in busy, stressful environment where there are competing demands and frequent distractions [3] [4]. Nurses need to make their decisions quickly and accurately to prevent the deterioration of patient condition to a life threatening situation. In addition, dealing with sophisticated new technology, such as cardiac monitor, highly unstable and seriously ill patients with lack of resources, a great burden is put on intensive care nurses to find the best clinical choices and affect their decision making abilities.

Decision making is described in the literature interchangeably and uses a number of terms such as clinical judgment, decision making and clinical reasoning. While these terms are used interchangeably, they have been described as "a choice made by a practitioner from a number of alternatives" [5] (p. 16). Clinical decision making is a complex process that requires nurses to be knowledgeable, have access to an appropriate information sources and work within a supportive environment [6]. As the nurse's professional role expands, they become responsible for a wider range of clinical decisions [7]. Clinical decision making requires nurses to be experienced and knowledgeable in relevant aspects of nursing [8] and consequently the decision making process becomes easier and more manageable [8]. Nurses have to decide what the problem is, what information to collect, how to treat the problem, if the treatment is effective or whether the patient needs medical review for further investigation and treatment.

Nurses in critical care areas make many critical decisions. Although the professional role of nurses has extended and become more responsible, these added responsibilities serving for wider decision making [5]. Corcoran [9] argues that the more complex the task, the more complex the decision making and the higher the likelihood that an incorrect decision will be made. This is supported by Tanner et al. [10] who stated that decisions are more difficult when tasks are more complex; however the process of decision making becomes easier and manageable when the nurses become more experienced [8].

\section{Literature Review}

The critical care nursing role has been expanded in response to new knowledge, political pressure and technical advances in health care. Decision making is considered as a complex process and it is important at all levels of the management process and comprises of different levels of complexity [11]. Effective decision making depends on the accuracy of assessments and the inferences that are drawn from nurses before action being taken [12].

Ersoy and Akpinar [13] conducted a study to assess the opinions and roles of intensive care unit (ICU) nurses regarding the distribution of ICU beds. A self-administered questionnaire was filled by 136 nurses at two national intensive care congresses in Turkey. The study found that more than half of the nurses were participated in the process of admission/discharge decisions. The study also found that the length of nurse's experience contributes to the nurse's involvement in these decisions and challenge the physician decision regarding patient's discharge. Furthermore, experienced nurses who have critical thinking ability expect to make good clinical decisions. The finding 
showed the importance of the patient advocate role for nurses. However, the nurses' decision regarding the quality of life was not taken as a criterion guiding admission and discharge.

In a study undertaken by [14] to explore the reasoning strategies and criteria used by critical care nurses in Iran in making decisions. They found that intuition and recognizing similar patient's situations were important strategies used by nurses to diagnose the patient's health problem and provide appropriate care. An important finding in the study was that nurses would decide whether they would carry out decisions based on the patient's risk-benefit and organizational necessities, although they are competent of making such decisions. This was related to the fact that nurses had a limited level of autonomy in making decisions regarding the patient's health situation. In another study, Decision making processes have been examined by comparing expert and novice nurse's decision making in their natural setting (ICU). The decision making of four (n $=4)$ expert and four $(\mathrm{n}=4)$ novice nurses were compared in regarding cue usage and clustering during the post-operative period. Hoffman et al. [15] found that expert nurses collected a wide range of cues $(n=89)$ which amounted to twice than that novice nurses and almost the same numbers of cues in relation to hemodynamic status. Importantly, expert nurses were found to obtain the whole picture of the patient's situation by incorporating the collected cues with the test results and other information in order to assess the patient's problem. This confirmed that experts had an intuitive grasp of the patient health problem and did not depend on the analytical approach to make decisions on the appropriate action.

The current study sought to increase the understanding of decision making process's used by nurses in a clinical environment. Due to the complexity of the critical care unit, nurses may face enormous challenges as they are caring for patients with life threatening conditions. By examining critical care nurses' decision making, it may be possible to identify the strategies that could help them improve the process of decision making and to help them recognize patterns in assessing and managing patient's situation appropriately. To increase our understanding of the real world decision making in a naturalistic study is required to include the interaction of task, person, and environmental factors.

In Jordan there are no research studies that explored the clinical decisions made by ICU nurses. Therefore, understanding the decision making process that nurses undertake when faced with a deteriorating patient and knowing why they made their decisions provides considerable insight into how the variation in nurses' clinical decision making occurs and how to improve a nurses clinical decision making. An understanding of how critical care nurses decision making occurs can be valuable for the nurses as they try to enhance the efficiency of their nursing care. Accordingly, the purpose of this study was to describe the decision making process and decision activities of critical care nurses in natural clinical settings.

\section{Methodology}

This exploratory descriptive study was based on naturalistic decision making. Data was 
generated through overt participant observation and in-depth interviews. Three critical care units in the city of Amman were involved in the study. Twenty-four critical care nurses from the three units, with at least 3 years of experience, were participated in the study. Participant observation was performed by expert nurses during nurse's shifts to see the routine clinical decisions made by ICU nurses. About 150 hours of observations were spent in the involved intensive care units. In-depth semi structured interview was conducted with each participant to assure further understanding of the way participant shaped their clinical decisions in critical care units. Interviews were tape-recorded and later transcribed verbatim. Tape recorded interviews were transcribed verbatim by the main researcher. Data obtained from transcribed interviews were analyzed by the researcher using thematic analysis [16]. Themes within data was identified, analyzed and reported to describe shared practice and common meanings.

Sampling method: Three critical care units in the city of Amman were involved in the study. Twenty-four critical care nurses from the three units were participated in the study (Table 1). Participant selection was guided by a set of criteria: being a registered nurse; having at least one year's experience, and (3) being willing to participate. The selection of participants who had at least 3 years of experience was to ensure they had enough experience to share. Prospective participants were verbally invited, which was followed with an outline of the study, and they were encouraged to ask questions and seek clarification. Those who wished to take part were asked to sign a consent form. However, the sample size would depend on data saturation.

Ethical consideration: Permission to conduct the study was obtained from the involved hospitals prior to commencing data collection. Verbal and written information about the study was given to each potential participant. Participation was voluntary and based on written informed consent. Participants were informed that they could withdraw at any time and that all data would be treated confidentially.

Rigor of the Study: The credibility of this study established by both prolonged engagement with the topic and the length of time spent in contact with the participants. This would enhance data sensitivity by decreasing the disagreement between the meanings assumed by the researcher and those understood by the target population.

Table 1. Summary of the participants' characteristics: $\mathrm{N}=24$.

\begin{tabular}{ccc}
\hline Category & \multicolumn{2}{c}{ Number } \\
\hline \multirow{2}{*}{ Age } & $25-34$ & 16 \\
& $35-45$ & 7 \\
Gender & $>45$ & 1 \\
& Female & 19 \\
Educational level & Male & 5 \\
& Bachelor & 20 \\
& MSc & 4 \\
Nurse experience (years) & $3-5$ & 10 \\
& $5-10$ & 7
\end{tabular}


Furthermore, I have audited every transcript against the original audio tape by repeatedly reading the typed transcript and comparing this to the audio-recording. This has enabled me to become extremely familiar with the data and consequently gain confidence in its overall trustworthiness and the accuracy of my analysis. Direct quotations from the transcribed text were also used to ensure that the perspectives of the participants are represented as clearly as possible in the study findings.

\section{Results}

During the course of the study, making decisions is appreciated as one of the main qualities of being a critical care nurse and an essential element of the practice of critical care nursing. Critical care nurses are constantly faced with situations where they have to make informed decisions. Some of these decisions may involve the nurse only, while other decisions would involve medical staff and other members of the health team. Decisions taken by the critical care nurses vary between simple routine decisions and highly complicated ethical decisions. In the following presentation of the findings, we will attempt to address the main themes that were observed by the researchers or addressed by the nurses in the unit.

\subsection{Ongoing Process}

During the course of the study decision-making process has proved to be an on-going process in critical care setting, i.e. critical care nurses are taking decisions all the time during their clinical practice. "There is just on-going decision throughout the shift, ... you' ve got to a point in the shift where you ask. what do you do next?, planning your next set of activities, prioritising, reassessing all the time, there is quite a constantly decision making".

"We are deciding all the time about when to reduce drugs, when to increase drugs, or perhaps if you think a different drug should be used you can suggest that to the doctors, feeding maybe, increasing feeding or if you think a person should be tried with oral fluids if they are at a stage when you think they could cope with them, or different types of nutritious drinks that they could have or soft diet. If you think the dietician could help in any way you can always, involve the dietician..., lots of things really, lots of things all the time".

"There are all sorts of decisions that you have to make here. Some are almost unconscious, not consciously made, some are very much a consultative deliberation, you have to be very careful about what you' re going to do... I would say probably when you look at the actual decisions you make each day, you probably make about $95 \%$ of them alone. There is probably not very many that you have to refer on for. Because obviously decisions can be anything from when to zero your lines [calibrate the machines according to a standard measures], when to check equipment, when to administer certain drugs, when to turn the patient. I would say $95 \%$ of the time you don't have to refer on, it's only something tricky you might refer on or something where you physically have to have another pair of hands to do it, you might refer on for". 
In spite of these comments by the nurse, it was obvious for that there are many team-decisions that are taken jointly by the nurse and the doctor and sometimes other members of the health team. These decisions are usually related to adjusting therapy and manipulating bodily functions. They are usually decisions that may have serious consequences on the patient's condition or may provoke ethical controversy. The nurses strongly believe that ethical decisions and life-threatening decisions should be a group decision rather that taken by a single person. In this instance, many critical care nurses believe that their opinions and suggestions are valued by physicians more than nurses in other areas. According to some nurses, this is so because they spend all their time at the patient's bedside and they have a certain degree of knowledge which makes the medical staff trust their judgment. It is probably fair to say that critical care nurses do feel different from and sometimes superior to other nurses who work in other areas in the hospital especially word nurses.

\subsection{Autonomy}

Critical care nurses believe that these qualities that they possess and the unique environment of critical care entitle them to a degree of autonomy. Some nurses would in fact take some "pure" medical decisions and act upon them before asking the medical staff. The nurses would usually ask the medical staff to approve such decisions after they have actually been implemented. The following are based on observations within the critical care units.

"The sister took some blood from the patient in order to test for blood gases, sugar and electrolyte. I went with the sister because she wanted to show me how to use the machine that they use to give instant analysis of blood samples that they have in the unit, as every nurse should be shown how to use it. The test results took about three minutes to come through. The gases were OK, but the blood sugar was very low (1.3 $\mathrm{mmol} / \mathrm{L})$. So she said that she 'had to rush back to give the patient some glucose'. When we reached the patient we found that the renal doctor was already there and was writing some notes on the patient's sheets. The sister prepared $50 \mathrm{ml}$ of $50 \%$ glucose solution and started to give them to the patient through his central line. While she was doing that, she asked the renal doctor to write down the amount of glucose that she is giving. She did that as if she was stating the obvious, because she had already determined the amount of glucose to be given which is something usually left to the medical staff to decide. But as I said, she seemed to know what she is doing and she wanted the doctor to know that as well, because she only asked him to confirm that in writing for legal purposes only". Obs-12.2

Although the intervention that the nurse implemented in the above mentioned situation seems obvious, the incident still shows how some critical care nurses regard themselves as entitled to take an advanced role in patients' care. Once again, it is through experience that the critical care nurses become more aware of what they can decide on. The nurses' accounts and the observational data suggested that the degree of power and confidence increase with more experience in critical care. 


\subsection{Experience, Power and Intuition}

It is probably credible to suggest that the nurses' involvement in decision making is a process of maturation. When the nurse is lacking the experience she or he tends not to take any decision that might involve power testing between the nurse and other members of the health team, particularly doctors. On the other hand the experienced nurse is willing to take the risk of crossing the power line between the nurse and the doctor by taking some non-nursing decisions or questioning some controversial decisions taken by the doctor. In the above-mentioned incident, if the nurse was not experienced enough, most probably she would not have acted in the same way she did. Perhaps, she would have consulted the doctor before she gave the patient the drug he needed. Similarly, the doctor's reaction to the incident would also be different if the nurse involved was less experienced, i.e. less powerful. One experienced nurses stated that:

"They [the patients] can't speak for themselves so I don't think the doctors, I think the medical staff try and get the best for the patients as well, but it is just the nurse at the bedside, from experience and from intuition sort of, gets a feel for the patient. So you get to know how the patient responds to particular drugs, if, I don't know, if a particular laxative suits them better than another laxative, whatever really you just get to know them, its instinct and intuition and a lot of that gained from experience in the field. You get a feel, you don't get it straight away, when you start to look after a patient it isn't automatically there, you just get a feel for how they do respond to particular things and then you can sort of you know, you follow that pathway really. I think some of it is back to experience. ... $\mathrm{m}$ sure some of it is drawn from past experience and some of it you know, is intuition". 8.5

These attributes of learning from experience and intuitive decision making have been well documented in the pragmatic model of skill acquisition described by Benner [17] Benner et al. [18]. Nonetheless, while this might be true in regard to clinical decisions taken by the nurse at the bedside, it would probably be less applicable when it comes to making more difficult joint decisions such as ethical ones.

\subsection{Joint Decisions}

In general when talking about joint decisions in the critical care unit, nurses were referring to decisions made by the nurse and the doctor together. Decisions made jointly between nurses are less frequent in critical care although perceived as important by the nurses. Critical care nurses believe that group or joint decisions are very important in the practice of critical care. Being involved in decision making regarding patient care make the nurse feel valued and respected. Moreover, group decisions provide a consensus of opinions and reduce prejudice. One of the participating nurses said:

"I think as you get more senior then you obviously have more say in a group decision, but people have to feel valued whatever job they do and so then if they' re involved in a person's care then they really should have an opinion in a decision....I think everybody should be involved that's looked after the patient. They might have an opinion or an idea that nobody else has thought of ${ }^{\prime} .8 .6$ 
Once more, the nurse is suggesting that with more experience nurses would become more involved in group decisions and their opinions would be probably valued more. However, when making decisions or being involved in group decisions the critical care nurses are bound by certain professional and legal rules. The nurses have to know their abilities in making certain decisions and have to appreciate their level of accountability. This issue was raised by most of the participating nurses and may be considered to be crucial to the practice of critical care nursing. One nurse said:

"Well, for instance if somebody is dying, you are resuscitating them, then to not carry on resuscitating them is a group decision. You don't just say I think we should stop. ..., everybody has to agree, you can't just do it on your own". 8.7

The nurses' knowledge of the limitation of their decisions is learnt mainly through experience and extra training. With more experience in critical care, the nurses would realize what they can decide on and what they cannot. One nurse describing the way decisions are made in critical care setting.

"Obviously, I $m$ very aware that any decision I make I have to back up like I ve already said, and that there is a limitation to my decisions that I can't just suddenly decide that $1 \mathrm{~m}$ going to take somebody off a ventilator, that $1 \mathrm{~m}$ going to start weaning them, or whatever. But saying that I can make a decision and then go and find a doctor and say; $P$ ve decided $1 \mathrm{~m}$ going to do this, is it all right? but because $P$ ve got quite a lot a few years of experience behind me now and..., $P$ ve done extra training or whatever, $I$ feel I know what I can decide and what I can' $t^{\prime \prime} .8 .8$

Therefore, experience not only makes the nurses know their limitations when making decisions, but also gives them the confidence and knowledge necessary to back up their decisions or suggestions. This is particularly true when it comes to making ethical decisions in the intensive care unit.

\subsection{Advocacy}

Ethical decisions are described as part of everyday practice in the critical care unit. Critical care nurses are constantly faced with multifaceted ethical situations. Critical care nurses consider themselves to be the patients' advocate or 'spokesperson'. Nurses would stand out for the patients to protect them against any existing or potential harm. One nurse commented:

"I view myself, if I am looking after a patient, as standing in for that patient., and I protect the patient against people who might want to harm them as I perceive it like somebody wanting to do research on a patient, if I don't think that is appropriate for that patient then I will say so and I would document that. I would make sure that nobody would do anything that would hurt my patients". 8.9

One of the nurses expressed that:

"I see that the patients we have on here have no control, they have no voice, they have nobody rooting for them in their corner, ...the only person they have is they have family but family don't really understand $100 \%$ what is going on, no matter how much you try to inform them, ...it takes them along to grasp any sort of concept of just how ill 
they are sometimes. So the only voice they have is that of the nurse looking, ...looking after them. ...P $m$ there to be their voice". 8.10

This nurse believes that helping the patient to a dignified end is part of her/his advocacy role and moral obligations as a nurse. Probably that is why the issue of continuing or withdrawing treatment has always provoked ethical dilemmas in the critical care unit. Most nurses would speak out their minds if they feel that a certain decision was inappropriately taken or not legitimately implemented. This is particularly true when the decision is concerned with withdrawing life sustaining treatments or interventions. One nurse stated.

" $A$ lady who I had looked after on before my days off who had been diagnosed as having, ...an empyema, and was very sick. But when I got back she was on a diamorphine infusion. They'd said that you know, there's no more they could do for her, ...now I felt that before I went off she had a good blood pressure, there was nothing really that had happened to her actually... if she hadn't gone into renal failure, she hadn't got an MI [myocardial infarction], they'd just decided that she was in her $70 \mathrm{~s}$, she had an empyema, and that really her quality of life is very poor, that was it really, why she's on a diamorphine infusion. So two of us actually felt that it was a wrong decision and went to the consultant and explained how we felt. He'd actually thought she was diagnosed with a malignancy which she wasn't, it never came back as a malignancy. So at that they resumed treatment and she got better and she went home after a while". 8.11

Accordingly and despite overwhelming hindrance, critical care nurses are, in most instances, able to act in a moral manner. Nurses sometimes even have to engage in somehow risky behavior in order to fulfill their professional and moral obligations. Confronting physicians and or breaking some organizational rules are examples of such risky behavior.

\section{Discussion}

The present study examined decision making of nursing staff working in Critical Care Units. Critical care nurses use many sources of information, such as their experience, knowledge, stories about their patients, and advice from their colleagues and doctors. The difficult and complicated health situation in critical care areas highlight the complexity and the importance of nurses decision making [14]. Patients in critical care units are seriously ill and frequently unstable and their health changed rapidly [14] [19] [20]. These changes require the nurses to make decisions in a limited period of time [4].

The process of decision-making has been described as an ongoing process in the intensive care unit, i.e., constantly practiced on everyday practice. The nature of the decisions that are taken within the critical care setting depends mostly on the situation, taken by the nurse unconsciously and considered as part of their everyday practice. There are certain decisions which are taken by the nurse who is looking after the patient and there are those joint decisions which are taken by both the nurse and the doctor. Nevertheless, there are lots of "grey" areas where the nurses' and doctors' roles are 
interrelated to a great extent. Some (normally) purely medical decisions are taken sometimes by critical care nurses or at least suggested by them.

The findings of this study revealed that experience is one of the main factors that determine the nurses' ability to take decisions. Clinical experience where found to positively strengthen nursing care [13] [20]. Through experience, the critical care nurses become more aware of their role in decision-making process. Arbon [21] stated that, through experience, nurses become (i) more comfortable and confident in their clinical practice, (ii) more comfortable and confident with their ability to provide safe nursing care, (iii) with their performance and acting in a purposeful and therapeutic way and (iv) better motivated to understand others' lived worlds. Experience also is believed to give nurses power and credibility and is considered as the main backup for the intuitive actions which the nurses do. The experienced nurse makes clinical decisions based on cues she or he identifies in the situation. These cues are learnt from previous knowledge and experience [9]. The experience comes from recognizing patient's health situations and then developing action strategies to manage these situations [22]. The findings in this study concurred with those of [4] [14] [23] [24] [25] [26] [27] in that experience is a factor influencing nurses' clinical decision making.

Critical care nurses are particularly concerned with being the patients' advocate because of the state of the patients who they nurse. Nurses consider critically ill patients to be vulnerable and powerless. In more difficult situations where the decision might carry the risk of provoking clinical or ethical controversy, a joint approach of decision-making is usually applied mainly between the nurse and the doctor. In such situation, the critical care nurses consider themselves as the patient advocate who is there to protect the patient against existing or potential harms. In addition, the nurses see the patients' families as a support system that would have an advocate role as well. Nevertheless, nurses often think that the families do not have the necessary knowledge and understanding which is required to exercise their role. Therefore, the nurses think of themselves as the main voice that the patients have. The nurses believe that experience and knowledge give them the ability to exercise this role and fulfill their moral and professional obligations.

The findings suggested that clinical decisions taken by the nurses are likely to be intuitive in nature rather than rationale. King and Macleod Clark [28] support this, in their study that explored nurses' understanding and use of intuitive decision making in clinical practice in Australia. This means that critical care nurses usually make clinical decision based on their experience in similar situation and in accordance with cues they identify in the clinical situations they face. It is rather obvious that this finding is consistent with the skill acquisition model suggested by Benner [17] who suggested that this intuitive decision-making ability comes from years of practice and knowledge accumulated from similar situations or paradigm cases. Nevertheless, it does not mean that the nurse is taking the first opportunity to resort back to rituals, rather the experienced nurse can adapt to rapidly changing patient situation and taking the right action at the time to achieve the desired result for the patient [29] [30]. 
Having assumed that clinical decisions are taken usually by the nurses in an intuitive manner, we do not intend to imply that the critical care nurses do not follow a rational approach in their practice. Rather, we suggest that all intuitively taken decisions are in some way based on subconscious rational knowledge. In fact, it is not argued that rational and intuitive decision-making are mutually exclusive. Both approaches co-exist in the everyday practice of the critical care nurse. Although nurses sometimes seem to be acting intuitively, they are depending on an accumulated knowledge that was established rationally. Therefore, the critical care unit is the area where rational and intuitive decisions can live in harmony and be acted upon confidently by the critical care nurses.

\section{Conclusion}

The study delineates critical care nurses ability in managing patients' situation and obtains more understanding of how and why they made clinical decisions. The findings of this study revealed that critical care nurses were able to respond to the patient's health situation in a continuous manner to prevent patient's case deterioration. It is generally accepted that nurses work toward providing the best outcomes of care and treatment through the implementation of evidence-based practice. The decision making process is influenced by many factors, in particular the nurses' clinical experience and nurses' interpretation of the available evidence derived from the patient. The findings of this study demonstrate that an intuitive model was apparent in nurse's clinical decision making. The process was dependent on the nurse's ability to understand the clinical situation of the patient which depends mainly on clinical experience. The study improves our understanding of the decision making process used by critical care nurses and how it enhances the quality of practice.

\section{Acknowledgements}

The authors would like to thank the Deanship of Academic Research at the University of Jordan for supporting this study. Gratitude is due to nurses who participated in this study.

\section{References}

[1] Aitken, L. (2003) Critical Care Nurses' Use of Decision Making Strategies. Journal of Clinical Nursing, 12, 476-483. https://doi.org/10.1046/j.1365-2702.2003.00763.x

[2] Currey, J. and Worrall-Carter, L. (2001) Making Decisions: Nursing Practice in Critical Care. Australian Critical Care, 14, 127-131. https://doi.org/10.1016/S1036-7314(01)80030-8

[3] Alasad, J., Abu Tabar, N. and Ahmad, M. (2015) Patients' Experience of Being in Intensive Care Units. Journal of Critical Care, 30, 859-859. https://doi.org/10.1016/j.jcrc.2015.03.021

[4] Buchnall, T. (2000) Critical Care Nurses Decision-Making Activities in The Natural Clinical Setting. Journal of Clinical Nursing, 9, 25-36. https://doi.org/10.1046/j.1365-2702.2000.00333.x

[5] Hancock, H. and Durham, L. (2007) Critical Care Outreach: The Need for Effective Decision-Making in Clinical Practice (Part 1). Intensive and Critical Care Nursing, 23, 15-22. https://doi.org/10.1016/j.iccn.2006.06.003 
[6] O’Neill, E., Dluhy, N. and Chin, E. (2005) Modelling Novice Clinical Reasoning for a Computerized Decision Support System. Journal of Advanced Nursing, 49, 68-77.

https://doi.org/10.1111/j.1365-2648.2004.03265.x

[7] Dowding, D. (2008) Commentary on Banning M (2008) A Review of Clinical Decision Making: Models and Current Research. Journal of Clinical Nursing, 18, 304-311.

[8] Banning, M. (2007) A Review of Clinical Decision Making: Models and Current Research. Journal of Clinical Nursing, 17, 187-195. https://doi.org/10.1111/j.1365-2702.2006.01791.x

[9] Corcoran-Perry, S. (1986) Task Complexity and Nursing Expertise as Factors in Decision Making. Nursing Research, 35, 107-112.

[10] Tanner, C., Padrick, K., Wesfall, U. and Putzier, D. (1987) Diagnostic Reasoning Strategies of Nurses and Nursing Students. Nursing Research, 36, 358-363.

https://doi.org/10.1097/00006199-198711000-00010

[11] Bohinc, M. and Gradisar, M. (2003) Decision Making Model for Nursing. Journal of Nursing Administration, 33, 627-629. https://doi.org/10.1097/00005110-200312000-00003

[12] Bucknall, T. and Thomas, S. (1996) Critical Care Nurse Satisfaction with Levels of Involvement in Clinical Decisions. Journal of Advanced Nursing, 23, 571-577.

https://doi.org/10.1111/j.1365-2648.1996.tb00021.x

[13] Ersoy, M. and Akpinar, A. (2010) Turkish Nurses' Decision Making in the Distribution of Intensive Care Beds. Nursing Ethics, 17, 87-98. https://doi.org/10.1177/0969733009349992

[14] Ramezani-Bader, F., Nasrabadi, A. and Yekta, P. (2009) Strategies and Criteria for Clinical Decision Making in Critical Care Nurses: A Qualitative Study. Journal of Nursing Scholarship, 41, 351-358. https://doi.org/10.1111/j.1547-5069.2009.01303.x

[15] Hoffman, K., Aitken, L. and Duffield, C. (2009) A Comparison of Novice and Expert Nurses' Cue Collection during Clinical Decision-Making: Verbal Protocol Analysis. International Journal of Nursing Studies, 46, 1335-1344. https://doi.org/10.1016/j.ijnurstu.2009.04.001

[16] Braun, V. and Clarke, V. (2006) Using Thematic Analysis in Psychology. Qualitative Research in Psychology, 3, 77-101. https://doi.org/10.1191/1478088706qp063oa

[17] Benner, P. (1984) From Novice to Expert: Excellence and Power in Clinical Nursing. Addison-Wesley, Menlo Park.

[18] Benner, P., Tanner, C. and Chesla, C. (1992) From Beginner to Expert: Gaining a Differential Clinical World in Critical Care Nursing. Advance Nursing Science, 14, 13-28. https://doi.org/10.1097/00012272-199203000-00005

[19] Darawad, M., Al-Hussami, M., Saleh, A., Al-Sutari, M. and Mostafa, W. (2014) Predictors of ICU Patients' Pain Management Satisfaction. Australian Critical Care, 28, 129-133. https://doi.org/10.1016/j.aucc.2014.07.003

[20] Thompson, C., Dalgleish, L., Bucknall, T., et al. (2008) The Effects of Time Pressure and Experience on Nurses' Risk Assessment Decisions. Nursing Research, 57, 302-311. https://doi.org/10.1097/01.NNR.0000313504.37970.f9

[21] Arbon, P. (2004) Understanding Experience in Nursing. Journal of Clinical Nursing, 13, 150-157. https://doi.org/10.1046/j.1365-2702.2003.00861.x

[22] Gunnarsson, B. and Stomberg, M. (2009) Factors Influencing Decision Making among Ambulance Nurses in Emergency Care Situation. International Emergency Nursing, 17, 83-89. https://doi.org/10.1016/j.ienj.2008.10.004

[23] Cioffi, J. (2000) Nurses' Experiences of Making Decisions to Call Emergency Assistance to Their Patients. Journal of Advanced Nursing, 32, 108-114. 


\section{https://doi.org/10.1046/j.1365-2648.2000.01414.x}

[24] Cioffi, J. (2001) A Study of the Use of Past Experience in Clinical Decision Making in Emergency Situations. International Journal of Nursing Studies, 38, 591-599.

https://doi.org/10.1016/S0020-7489(00)00096-1

[25] Bakalis, N. (2006) Clinical Decision-Making in Cardiac Nursing: A Review of the Literature. Nursing Standard, 21, 39-46.

[26] Currey, J., Botti, M. and Browne, J. (2003) Hemodynamic Team Decision Making in the Cardiac Surgical Intensive Care Context. Heart and Lung, 32, 181-189. https://doi.org/10.1016/S0147-9563(03)00041-4

[27] Currey, J., Browne, J. and Botti, M. (2006) Haemodynamic Instability after Cardiac Surgery: Nurses' Perceptions of Clinical Decision-Making. Journal of Clinical Nursing, 15, 10811090. https://doi.org/10.1111/j.1365-2702.2006.01392.x

[28] King, L. and Macleod Clark, J. (2002) Intuition and the Development of Expertise in Surgical Ward and Intensive Care Nurses. Journal of Advanced Nursing, 37, 322-329. https://doi.org/10.1046/j.1365-2648.2002.02105.x

[29] Darawad, M., Nawafleh, H., Maharmeh, M., Hamdan-Mansour, A. and Azzeghaiby, S. (2015) The Relationship between Time Pressure and Burnout Syndrome: A Cross-Sectional Survey among Jordanian Nurses. Health, 7, 14-22. https://doi.org/10.4236/health.2015.71003

[30] Saleh, A., Darawad, M. and Al-Hussami, M. (2014) Organizational Commitment and Work Satisfaction among Jordanian Nurses: A Comparative Study. Life Science Journal, 11, 3136.

\section{Submit or recommend next manuscript to SCIRP and we will provide best service} for you:

Accepting pre-submission inquiries through Email, Facebook, LinkedIn, Twitter, etc. A wide selection of journals (inclusive of 9 subjects, more than 200 journals)

Providing 24-hour high-quality service

User-friendly online submission system

Fair and swift peer-review system

Efficient typesetting and proofreading procedure

Display of the result of downloads and visits, as well as the number of cited articles

Maximum dissemination of your research work

Submit your manuscript at: http://papersubmission.scirp.org/

Or contact health@scirp.org 